\title{
The future prospects for living wills
}

\author{
David Greaves University of Wales, Swansea
}

\section{Author's abstract}

Following the first enactment of living will legislation in California in 1976 the majority of the states of the USA have now passed similar laws. However, flaws have been identified in the way they work in practice and many states are considering reviewing their legislation. In Britain there is no legislation but the subject is currently commanding considerable interest. This paper assesses the future prospects for living wills in both the USA and Britain, analysing the different options available and comparing the two countries.

If patients who become permanently incompetent are to have their previous autonomous decision-making respected, there is general agreement that advance directives for health care must be introduced. The difficulty is in deciding how to implement them, and especially whether this should be by statutory or non-statutory means, the traditions in the two countries being very different in this respect. It is concluded that whichever route is taken, promoting respect for patient autonomy is as much a matter for education and persuasion of doctors as of the adoption of particular instruments. Doctors should therefore be trained in what constitutes good medical practice in this area and, to ensure that it can be carried out properly, the general level of medical facilities for these patients must also be protected and promoted.

\section{Introduction}

In 1976 California enacted the Natural Death Act, the first legislation to deal with living wills. The ethical principle which underpinned the introduction of law in this new area was the desire to enhance patients' autonomous decision-making should they become incompetent to make their wishes known, and so to protect them from the indignity, suffering and pain to which undesired continued life-sustaining treatment might lead. Referring to the same ethical principle the majority of the states in the USA have now passed similar laws, relating either to living wills, durable powers of attorney, or a combination of the two. These legal instruments have become known collectively as

\section{Key words}

Living wills; enduring power of attorney; advance directives for health care; dying; death with dignity. advance directives for health care. A living will is the name which has been adopted for a document which allows a competent person to request and direct that $\vec{v}$ certain measures be taken should he become incapable of taking responsibility for his own health care. A durable (or enduring) power of attorney in the context $\mathrm{O}$ of health care, allows a person, whilst competent, to appoint an agent to act on his behalf, in specified matters of health care, if and when he becomes incompetent.

A survey conducted early on to examine the effects of the original Californian legislation, suggested that it had been largely unsuccessful in achieving its purpose because it had been drafted too narrowly and was bein interpreted by the physicians in a restrictive manner. (1). Similar concerns have been expressed mo recently in a general review by Heintz of the operation of the various state laws (2). Heintz identified two major flaws that have found their way into many states' legislation. These are, first, that patients must be certified 'as qualified' in order to have their advance directives respected and, second, that statutes frequently apply only to terminally ill patients. The problems caused have been summarised as follows:

Both restrictions, argues Professor Heintz, tend in practice to mean that the prior competent wishes of patients who are not certified 'as qualified' are even less influential in their medical care once they have become incompetent than was the case before the advent of 'liberalising' living will legislation. Such problems are particularly likely to arise where the statutes do not explicitly preserve existing common law rights, notably to refuse medical treatment (3).

These and other concerns about the operation of the present statutes are now leading some states to consider revising their legislation. Also, in Britain, where there is no legislation, the subject is currently of considerable interest, and a multidisciplinary working party convened by Age Concern England and the Centre of : Medical Law and Ethics of King's College, London University, has published a report entitled The Living Will (4) reviewing the medical, ethical and legal issues as they relate to the British context. It would, therefore, seem an appropriate time to reflect on what 2 
the future of the law and of practice in this area should be in both the USA and Britain, drawing in particular on some of the observations of the British Living Will Report which considered much of the experience of the USA in reaching its conclusions. The different options available will therefore be analysed and reviewed, and comparisons drawn between the USA and Britain. Particular attention will be paid to the practical effects of legislation and whether these are likely to achieve their intended goal.

\section{The issues to be considered}

The initial question to consider is why Britain has not introduced legislation, in contrast with most of the states of the USA. There are two main reasons. First, in Britain there is generally far greater caution in resorting to the law in the regulation of medicine than there is in the USA. Secondly, as a rule, medical practice in Britain is less interventionist than in the USA, and this applies especially to the continuation of life-sustaining treatment and care. Of particular interest in considering the second of these reasons is that it does not appear to stem from differences in the ethical and legal principles adopted in the two countries, both of which accept that patients' clearly expressed wishes should be respected. The exact position in English law cannot be stated with certainty, as it has not been tested in the courts, but it is most probable that the following view would be accepted:

'If the patient had foreseen the circumstances which have since arisen and there is no reason to believe that he would have changed his mind if still capable of doing so, the doctor should only be justified in proceeding to the same extent as he could if the patient were still capable of consenting' (5).

This reasoning follows very closely the current position in the USA, exemplified by the New Jersey Supreme Court decision in the case of Conroy (6) which, in determining how to proceed in withholding or withdrawing treatment, in cases where the patient has become incompetent, laid down three tests to be applied. The two most important are as follows. In the subjective test to be applied where the patient's wishes are clearly known, whether expressed orally or in writing, these should be determinative. In the pureobjective test to be applied where the patient's wishes are not known treatment should be withheld or withdrawn where it would 'clearly and markedly outweigh the benefits the patient derives from life'. In each case, artificial feeding and hydration are to be included.

It seems then that it is differences in the norms of medical and legal practice in the two countries, rather than of ethical or legal principles, which lead to the disparities between them. This demonstrates the need to pay attention to 'cultural' influences in determining the likely acceptability of particular changes in the law. It also suggests that in each jurisdiction the whole situation should be considered afresh, rather than accepting that certain practices which have already been adopted in particular places are necessarily the right ones for elsewhere.

The next question then is whether it is desirable to introduce advance directives for health care at all. In Britain, the principal argument for not doing so and for retaining the status quo is that it is theoretically possible for any person to convey her wishes to her doctor, who may then act upon them should the person later become incompetent. The sentiment underlying the position was well expressed by Higgs.

'Nobody could claim that living wills will ever be a real substitute for empathic communication between health workers, patients, and relatives. Certainly the best results are likely to arise from continuous care by a practitioner who "knew the patient's mind" (7).

Whilst the intention behind this statement can only be endorsed, the problem with it is that there is no evidence that doctors in Britain regularly elicit such views from their patients, or that they document them so that they are available for use by other doctors at a later date. Also, even if such views were communicated and recorded, there would be no obligation on the doctor to take notice of them, should he not consider them appropriate for whatever reason. It is therefore difficult to imagine that the objective of promoting respect for the autonomy of the incompetent patiente can be advanced without some positive initiative, whether statutory or non-statutory.

A further question is whether the situation might be resolved, not through the implementation of advance directives, but simply by improvements in medical practice. As we have seen, doctors in both the USA and Britain have an ethical and legal duty to forego medical treatment for incompetent patients who have not made their wishes known, and where the burdens of treatment outweigh the benefits. Many doctors do not fulfil their obligations to their patients in this respect, either through ignorance or personal conviction, so that overall decision-making is variable and arbitrary according to which doctor the patient happens to come under. It may well be that this applies as much to doctors who withhold appropriate treatment in some cases, as well as in the more familiar cases where doctors continue with unduly burdensome treatment. Therefore, there is a great need for education of doctors to bring about improvements in medical practice in this respect, and it might be expected that if they were conscientiously carried through, such changes would lessen patient anxiety about the care they would be likely to receive and so lead to a diminution in demand for the use of advance directives. However, this would not in itself enable the individual and varying wishes of different patients to be respected. Thus, although such good medical practice is important and desirable in its own right, it must be regarded as complementary to, rather than as 
a substitute for, initiatives to introduce advance directives.

There is also a need to improve the general level of health care facilities for those groups of incompetent and mostly elderly patients who are being considered. Services for these patients have traditionally been relatively neglected and without improvement could well lead to requests for advance directives because of the fear of future dependence on poor facilities and care. In addition, the availability of advance directives could be used improperly as an excuse for not providing good facilities and care. Both these dangers must be guarded against if advance directives are to achieve their purpose.

Having established the need for some form of advance directive for health care and for the improvement of both medical practice and health care facilities, it is important to define which groups of patients should be included. One of the flaws identified in much current legislation is its limitation to terminally ill patients. This is clearly far too restrictive and the British Living Will Report proposed that the principal groups covered should be: the terminally ill; the seriously and permanently ill or disabled, who require treatment to stay alive but who, given such treatment, can stay alive for long periods; and those with severe and irreversible dementia.

The next question to be determined is what form advance directives should take and whether they should be introduced on a non-statutory or statutory basis. As previously noted, there are three possible types of advance directive to be considered: living wills, durable powers of attorney and a combination of the two. The advantages and disadvantages of each will therefore be considered.

The main disadvantage of living wills is the difficulty of drafting instructions which adequately reflect the patient's wishes and are effective in practice. If they only provide general directions they may lack sufficient content to guide the doctor as to how to act in a specific situation, and so be of little or no influence. On the other hand, if they provide specific instructions, the particular situation which arises may not have been foreseen so that, again, decision-making may not be influenced appropriately. These difficulties may be partly overcome by providing two sections in the living will to cover both general and specific instructions. The main advantage of the living will is that it entails a relatively simple procedure, especially if a standardised form is provided which is both straightforward and has been drafted so as to minimise the problems described.

Compared with living wills, durable powers of attorney have the disadvantage that, by depending on an agent to act on the person's behalf, some people will be debarred by not knowing of anyone who is suitable. Also, in the British Living Will Report, it is argued that durable powers of attorney can only be introduced on a statutory basis, because, if not, unresolvable disputes could arise between the designated agent and other interested parties. However, if it were statutory, it would inevitably be a more complicated procedure than a living will and so less attractive to many people. The necessity of making durable powers of attorney statutory is contested though, so these arguments may not hold. The main advantage of durable powers of attorney is that if the standard used is 'substituted judgement', ie a sympathetic interpretation of what the patient's own wishes would have been, then this is the best available mechanism for ensuring that they are carried out in the light of the particular situations which may arise.

\section{Future prospects}

Experience in the USA suggests that the separate advantages of living wills and durable powers of attorney are complementary and there is a strong argument for combining them. This allows the general outline of the principal's wishes to be stated in a living will, providing a context within which the agent can make more specific decisions depending upon the actual circumstances of the case. Such an arrangement has the added advantage that it provides a check on whether the agent's decisions are consistent with the general directions of the living will. There is a growing consensus that the most satisfactory way of ensuring that advance directives for health care are successful is to adopt this combined approach.

The more problematic question is whether advance directives should be available on a statutory or non statutory basis and this will now be considered (with the question of whether durable powers of attorney have to be statutory set aside). Where there has been no previous legislation the advantages of a non-statutory approach are that it can be implemented with a minimum of formal procedures; that it allows the ground to be tested, and that it would be more likely to be acceptable to doctors than legislation. The main disadvantage is that it would have no force in law, so doctors would not be obliged to follow the specified directions.

It is this sensitive area, concerning whether legislation is needed and will prove effective, which is perhaps the most difficult to assess. Returning to an earlier theme of the difference in general response between the USA and Britain, the solutions sought in and appropriate to the two countries will inevitably differ to some degree, despite their espousal of the same ethical and legal principles. However, these divergences should not be a bar to each country learning from the traditions of the other. Those states of the USA which have experience of legislation are unlikely to repeal it but in considering modifications they should take the opportunity to correct some of the problems which have already been identified. The British tradition of introducing the minimum of legislation which is required to achieve a particular end and of avoiding unnecessary confrontation with the medical profession should be noted. Britain, in its turn, has much to learn from the experience of the 
USA. First, although it is not acceptable to continue as at present, the introduction of legislation has been demonstrated to produce its own difficulties and should not be undertaken lightly. As Gillon states: 'It seems generally preferable to avoid legislation in the delicate area of personal medical care if the legitimate objectives of patients, health care workers and society can be achieved without it' (3). Such a view would require the introduction of non-statutory advance directives which, to be successful, would involve much greater knowledge on the part of the public and health care professions, and mechanisms for ensuring that peoples' wishes in this respect could be expressed and recorded. To prevent abuse such advance directives should also be set within a legal framework which would prevent the influence of any person having an interest in the early demise of the patient (8). A standardised and nationally available recognised form would greatly assist these purposes but even then the most serious concern about such a non-statutory scheme would be that doctors might still ignore the competently expressed wishes of patients when they disagreed with them. A general statement from the professional medical organisations expressing their commitment to respect advance directives would therefore be important. Unfortunately, this has not yet been made, and the British Medical Association, for example, in its recent report on euthanasia, was equivocal in its attitude to advance directives (9). Although the principle appeared to be accepted: '... a certified and settled wish by a patient should be treated with the utmost respect', putting it into practice was another matter: 'Any attempt to treat advance declarations as more than an indication of a patient's wishes where there are difficult decisions to be made is inappropriate'. Therefore the possibility remains that non-statutory change might prove ineffective and that legislation should be considered. If this were necessary the problems noted in the USA with present laws, and the developing experience of the revision of legislation, should be carefully noted.

The final conclusion must be that the success of any attempt to introduce advance directives, whether statutory or non-statutory, relies in large part on their acceptance by the medical profession and a willingness to operate them in the spirit intended. A non-statutory scheme can be ignored by doctors if they wish, but equally a statutory scheme can be resisted or obviated, at least in part, by doctors who are determined not to accept it. Therefore the most important lesson is that promoting respect for patient autonomy in the area of health care being considered is as much a matter for education and persuasion of doctors, as of legal and quasi-legal instruments. Whatever programmes are developed, whether in the USA or Britain, education, research and monitoring must be key elements in ensuring success. Consequently, such programmes should recognise the importance of training doctors in what constitutes good medical practice in relation to their decisions about withholding or withdrawing lifesustaining treatment, and also of the more general need to promote and protect good levels of medical facilities and care for those groups of patients being considered.

\section{Acknowledgement}

I would like to thank Dr Raanan Gillon for his help and comments in preparing this paper.

David Greaves MB BS MLitt is a Fellow at the Centre for the Study of Philosophy and Health Care, Swansea University.

\section{References}

(1) Redleaf D L, Schmitt S B, Thompson W C. The Californian Natural Death Act: an empirical study of physicians' practices. Stanford law review 1979; 31:913945.

(2) Heintz L L. Legislative hazard: keeping patients alive, against their wills. Fournal of medical ethics 1988; 14:8286.

(3) Gillon R. Living wills, powers of attorney and medical practice [editorial]. Fournal of medical ethics 1988; 14:5960.

(4) A Working Party Report. The living will. London: Edward Arnold, 1988.

(5) Skegg P D G. Law, ethics and medicine. Oxford: Clarendon Press, 1984: 116.

(6) In re Conroy 486 A 2d 1209 [1985].

(7) Higgs R. Living wills and treatment refusal. British medical journal [editorial]. 1987; 295:1221-1222.

(8) Robertson G S. Dealing with the brain-damaged old dignity before sanctity. Fournal of medical ethics 1982; 8:173-179.

(9) Working Party to Review the British Medical Association's Guidance on Euthanasia. The euthanasia report. London: British Medical Association, 1988. 